\title{
Greater soil carbon stocks and faster turnover rates with increasing agricultural productivity
}

\author{
Jonathan Sanderman ${ }^{1, a}$, Courtney Creamer ${ }^{1, b}$, W. Troy Baisden ${ }^{2}$, Mark Farrell ${ }^{1}$, and Stewart Fallon ${ }^{3}$ \\ ${ }^{1}$ Agriculture \& Food, CSIRO, PMB 2, Glen Osmond, SA 5064, Australia \\ ${ }^{2}$ National Isotope Centre, GNS Science, Lower Hutt, New Zealand \\ ${ }^{3}$ Australian National University, Canberra, ACT, Australia \\ a current address: Woods Hole Research Center, Falmouth, MA 02540, USA \\ ${ }^{\mathrm{b}}$ current address: USGS, Menlo Park, CA, USA \\ Correspondence to: Jonathan Sanderman (jsanderman@whrc.org)
}

Received: 11 August 2016 - Published in SOIL Discuss.: 18 August 2016

Revised: 29 November 2016 - Accepted: 12 December 2016 - Published: 4 January 2017

\begin{abstract}
Devising agricultural management schemes that enhance food security and soil carbon levels is a high priority for many nations. However, the coupling between agricultural productivity, soil carbon stocks and organic matter turnover rates is still unclear. Archived soil samples from four decades of a long-term crop rotation trial were analyzed for soil organic matter (SOM) cycling-relevant properties: $\mathrm{C}$ and $\mathrm{N}$ content, bulk composition by nuclear magnetic resonance (NMR) spectroscopy, amino sugar content, short-term C bioavailability assays, and long-term $\mathrm{C}$ turnover rates by modeling the incorporation of the bomb spike in atmospheric ${ }^{14} \mathrm{C}$ into the soil. After $>40$ years under consistent management, topsoil carbon stocks ranged from 14 to $33 \mathrm{Mg} \mathrm{Cha}^{-1}$ and were linearly related to the mean productivity of each treatment. Measurements of SOM composition demonstrated increasing amounts of plant- and microbially derived SOM along the productivity gradient. Under two modeling scenarios, radiocarbon data indicated overall SOM turnover time decreased from 40 to 13 years with increasing productivity - twice the rate of decline predicted from simple steady-state models or static three-pool decay rates of measured C pool distributions. Similarly, the half-life of synthetic root exudates decreased from 30.4 to $21.5 \mathrm{~h}$ with increasing productivity, indicating accelerated microbial activity. These findings suggest that there is a direct feedback between accelerated biological activity, carbon cycling rates and rates of carbon stabilization with important implications for how SOM dynamics are represented in models.
\end{abstract}

\section{Introduction}

Sequestration of carbon as soil organic matter (SOM) through shifts in land use and improvements in land management is seen as having the potential to offset a significant fraction of current greenhouse gas (GHG) emissions (Smith et al., 2008; Paustian et al., 2016) and be part of the necessary negative emission technologies that are increasingly believed to be needed to avoid dangerous levels of climate change (Smith, 2016) and also as an important stop-gap measure as nations transition to a low carbon economy (Read, 2008). A major reason for the prominent position soil carbon sequestration has in national GHG reduction agendas is because of the purported "win-win" situation of mitigating GHG while improving food security through improved soil health and cropland fertility (Tiessen et al., 1994; Oldfield et al., 2015).

What has been mostly lost in the debate is the concept that part of the biological utility of SOM in agriculture comes not from its accumulation but rather from its decay and subsequent release of nutrients and energy (Albrecht, 1938). Janzen (2006) eloquently argued that there may be a tradeoff between hoarding and using soil organic carbon (SOC), what he termed "the soil carbon dilemma". The argument goes that, while sequestering carbon as SOM, there are nutrients and energy that must remain non-available to plants 
and microorganisms in association with this new $\mathrm{C}$ because of stoichiometric constraints (Manzoni et al., 2010). These nutrients are only then released upon decomposition of the SOM. Some researchers (e.g., Lam et al., 2013; Kirkby et al., 2014) have gone as far as putting a monetary nutrient cost on SOC sequestration. This apparent trade-off is admittedly a bit simplistic because there are other longer-term benefits for hoarding SOC, including improved soil structure, increased water-holding capacity and greater potential to buffer against pH changes (Blanco-Canqui et al., 2013).

At the heart of this argument is the fundamental question of how carbon flow in soils is conceptualized and whether or not microbial physiology needs to be explicitly represented to accurately model SOC dynamics (Allison and Martiny, 2008; Lawrence et al., 2009). Microbes and the exoenzymes that they produce are the primary agents of decomposition. It would be logical to think that the activity and abundance of microbes and exoenzymes would be critical components of a SOC model, yet many SOC models can successfully simulate $\mathrm{C}$ dynamics at coarse scales by only implicitly representing microbial activity as static decay constants (Schimel, 2001). While these linear models generally work well, their predictive capacities may be limited (Sanderman et al., 2014) as evidenced by the large range of SOC responses $(-70$ to $+86 \mathrm{Pg} C$ change over the past century) reported for different terrestrial biosphere models by Tian et al. (2015). Microbe and enzyme-based SOC models produce greatly diverging predictions in response to major perturbations as compared to traditional linear models assuming implicit microbial physiology (Allison et al., 2010; Weider et al., 2013; Lange et al., 2015).

In addition to the elevated importance of soil microbes in SOC turnover models, there is mounting evidence from biochemical studies that the byproducts of microbial activity (i.e., microbial necromass) are dominant components of the stable SOM pool (Liang and Balser, 2008; Miltner et al., 2012; Cotrufo et al., 2013, 2015). If soil microbial activity is critical for both the decomposition and stabilization of SOM, then a better understanding of the microbial response to a major perturbation such as changing plant productivity would be critical to assessing the validity of the soil carbon dilemma.

In this study, we test whether or not there is a trade-off between sequestering and using SOC by utilizing a unique set of samples from a long-term agricultural trial in southern Australia. In particular, we exploit the spike in atmospheric ${ }^{14} \mathrm{CO}_{2}$ due to aboveground nuclear weapons testing to determine whether intrinsic SOC cycling rates (defined as the decay constants) differed among agricultural management regimes that make up a large productivity gradient. A change in SOC decay rates in response to management would indicate a biological feedback to SOC decomposition that is currently omitted from traditional $\mathrm{C}$ cycling models. The ${ }^{14} \mathrm{C}$ based soil carbon turnover rates are then supported by measurements of SOM chemistry and short-term soil microbial activity. Finally, we discuss the results in terms of biological controls on SOC cycling and how soil microbial processes are represented in carbon models.

\section{Materials and methods}

\subsection{Trial description}

The Permanent Rotation Trial at the Waite Agricultural Research Institute, South Australia, was established on a former open Eucalyptus woodland in 1925 to study the agronomic effects of 10 different cropping rotations, including the use of long fallows and pasture phases. The site has a Mediterranean climate typical of the region. Mean annual rainfall is $626 \mathrm{~mm}$, with $487 \mathrm{~mm}$ falling in the April-October growing season. Maximum and minimum mean annual temperatures are 21 and $12{ }^{\circ} \mathrm{C}$, respectively. The soil is classified as a Rhodoxeralf (USDA; Soil Survey Staff, 1999) or Chromic Luvisol (WRB; FAO, 1998) with a fine sandy loam texture in the upper soil horizons. Soil in the upper $10 \mathrm{~cm}$ had an average $\mathrm{pH}\left(\mathrm{H}_{2} \mathrm{O}\right)$ of 5.9 and a clay content of $18 \%$ (Grace et al., 1995). As most Australian soils are typically deficient in phosphorus (Richardson et al., 2009), a basal dressing of superphosphate fertilizer was applied annually across all managements. No nitrogenous fertilizers were used in the trial. Cultivars, cultivation and stubble management were consistent with typical district practice throughout the trial and have been detailed in Grace et al. (1995). Full agronomic production and climatic data records can be downloaded from the CSIRO Data Access Portal (doi:10.4225/08/55E5165EC0D29).

In this current study we have chosen to analyze archived soil samples from five plots representing a gradient in productivity: permanent pasture (Pa), 2 years of wheat followed by 4 years of pasture $(2 \mathrm{~W} 4 \mathrm{~Pa})$, continuous wheat (WW), wheat-oat-fallow rotation (WOF) and wheat-fallow rotation (WF). While every phase of each rotation was represented annually, we randomly chose one plot for each of these rotations (WF, WOF, 2W4Pa) for analysis. Detailed records of grain yield, aboveground dry matter production, pasture production and composition were kept for the duration of the trial. In 1963, 1973, 1983 and 1993 soil samples from the $0-10 \mathrm{~cm}$ layer were collected by compositing 20 soil cores taken along the $90 \mathrm{~m}$ length of each plot prior to sowing. Samples were dried in a forced fan oven at $40^{\circ} \mathrm{C}$ for at least $48 \mathrm{~h}$ before being stored in glass jars.

\subsection{Soil analyses}

All soil samples were analyzed for OC content $\left(\mathrm{mg} \mathrm{C}^{-1}\right)$ via high temperature combustion (LECO CNS-2000, LECO Corp., St. Joseph, MI). Soil OC stocks $\left(\mathrm{Mg} \mathrm{Cha}^{-1}\right)$ were then calculated by multiplying measured total organic carbon (TOC) values (mg Cg soil ${ }^{-1}$ ) with bulk density measurements $\left(\mathrm{Mg}\right.$ soil $\left.^{-3}\right)$ adjusted for sampling depth. No gravel correction was necessary. Bulk density (BD) was 
only measured in all rotations in 1997 (Baldock, 1998). To overcome this data limitation, we have developed a pedotransfer function using 132 samples from the 1997 dataset (see Appendix A), recognizing that since soil texture was similar across the trial, the main variation in $\mathrm{BD}$ will be due to changes in TOC content. This pedotransfer function $(\mathrm{BD}=-0.109 \times \mathrm{TOC}(\%)+1.543$, Fig. A1 in Appendix A) was then applied to the measured TOC values for the 19631993 samples. Given the small range in measured BD (1.251.58) across a 5-fold gradient in TOC, this approximation for $\mathrm{BD}$ appears to be the best of a range of options to minimize uncertainty and bias in calculated SOC stocks.

Mid-infrared spectroscopy in combination with partial least-squares regression (MIR-PLSR) was used to estimate the distribution of $\mathrm{OC}$ into three biologically meaningful pools, the particulate (POC), humus (HOC), and resistant (ROC) organic carbon fractions (Baldock et al., 2013a, b), using the Unscrambler X software package (CAMO Software, Oslo, Norway). Prediction statistics (Hotelling's $T$ square and Mahalanobis distance) suggested that this soil type was well represented in the calibration set of Baldock et al. (2013b). Given that the three fractions were predicted independently, the sum of the fractions did not always equal the measured TOC values (mean carbon mass balance $=101 \pm 5 \%(\mathrm{SD}))$. Thus, the predicted fraction data were adjusted to sum to the measured TOC values by calculating the fractional distribution of the MIR-PLSR predicted fractions (i.e., $\mathrm{POC} /(\mathrm{POC}+\mathrm{HOC}+\mathrm{ROC})$ ) and then multiplying these proportional allocations by the measured SOC stock.

Organic matter chemistry was assessed using solid-state cross-polarization magic-angle spinning ${ }^{13} \mathrm{C}$ nuclear magnetic resonance (NMR) spectroscopy and by quantification of amino sugars. Solid-state ${ }^{13} \mathrm{C}$ NMR spectra were obtained for the 1983 soil samples using a Bruker 200 Avance spectrometer (Bruker Corporation, Billerica, MA, USA) equipped with a $4.7 T$, wide-bore superconducting magnet operating at a resonance frequency of $50.33 \mathrm{MHz}$. Soils were first demineralized using $2 \%$ hydrofluoric acid (HF) to concentrate $\mathrm{C}$ and remove paramagnetic interferences (Skjemstad et al., 1994). The HF procedure resulted in an average $C$ loss of $17.4 \%$. Operating conditions were identical to those reported in Baldock et al. (2013a). In order to quantify absolute differences in chemical composition, data were reported by normalizing the recorded signal intensity by the amount of observable $\mathrm{C}$, determined following the conventions of Smernik and Oades (2000), in the analyzed sample.

Amino sugars, used here as a biomarker for microbial derived OM (Liang and Balser, 2008), were extracted and derivatized to form aldonitrile acetate derivatives from 300 to $500 \mathrm{mg}$ of ground soil following the procedure of Zhang and Amelung (1996) as modified by Liang et al. (2012). The aldonitrile acetate derivatives were identified and quantified relative to a six-point calibration curve containing all compounds of interest and relative to the internal standard (myo- inositol) on an Agilent $7890 \mathrm{G}$ GC and $5977 \mathrm{MS}$ using a 30 m DB-5 column (Agilent Technologies, Santa Clara, CA, USA). The recovery standard N-methylglucamine monitored derivatization efficiency.

Radiocarbon activity was measured by accelerator mass spectrometry at the Australian National University Radiocarbon Dating Laboratory (Fallon et al., 2010) and reported using the geochemical $\Delta^{14} \mathrm{C}$ notation (Stuiver and Polash, 1977). Analysis of radiocarbon data is presented in the next section.

To assess the short-term availability and turnover of carbon, we measured extractable OC, basal respiration, and the turnover of a ${ }^{14} \mathrm{C}$-labeled synthetic root exudate cocktail on the $0-10 \mathrm{~cm}$ samples from all plots and from all years with three analytical replicates. Extractable OC was quantified from a $0.5 \mathrm{M} \mathrm{K}_{2} \mathrm{SO}_{4}$ extract ( $1: 5$ soil : solution) on a Thermalox TOC analyzer (Analytical Sciences, Cambridge, UK). Basal respiration was measured as the $\mathrm{CO}_{2}$ accumulation in a $24 \mathrm{~h}$ period at $22^{\circ} \mathrm{C}$ on $5 \mathrm{~g}$ dry weight soil in a $50 \mathrm{~mL}$ centrifuge tube capped with a Subaseal using an infrared gas analyzer (LiCor Li-820, LI-COR Biosciences, Lincoln, NE, USA), after pre-incubation of 2 weeks at $60 \%$ water-holding capacity (WHC). The mineralization of ${ }^{14} \mathrm{C}$-tagged synthetic root exudates $\left(300 \mu \mathrm{g} \mathrm{Cg}^{-1}\right.$ soil, $\left.5 \mathrm{kBq} \mathrm{mL}^{-1}\right)$ was quantified over a period of one week in identically pre-incubated soils by liquid scintillation counting (Tri-Carb 3110 TR liquid scintillation counter and HiSafe 3 scintillation cocktail; Perkin Elmer Inc., Waltham, MA, USA) after trapping of respired ${ }^{14} \mathrm{C}-\mathrm{CO}_{2}$ in $1 \mathrm{M} \mathrm{NaOH}$. The synthetic root exudate cocktail, used to approximate the soil microbial community response to inputs of labile $\mathrm{C}$, consisted of $65 \%$ carbohydrates (glucose, fructose, sucrose; $2: 1: 1$ ), $30 \%$ organic acids (citrate, oxalate; $6: 4$ ) and $5 \%$ amino acids (glutamate, alanine, glycine; $2: 1: 1$ ) and was based on the chemistry of Zea mays root exudates (Kraffczyk, 1984). Root exudate C not taken up by the microbial community was quantified as ${ }^{14} \mathrm{C}$ remaining in $0.5 \mathrm{M} \mathrm{Na}_{2} \mathrm{SO}_{4}$ extracts of the soil at the end of the incubation; on average $5.1 \%$ of the added ${ }^{14} \mathrm{C}$ was recovered in the extract, indicating near-complete microbial uptake.

Root exudate-C mineralization was modeled by fitting a single first-order exponential curve (Paul and Clark, 1996) to the cumulative ${ }^{14} \mathrm{CO}_{2}$ data (curve fits shown in Fig. B1 in Appendix B):

Mass loss $=A+\mathrm{C}_{\min } e^{(-r t)}$,

where $A$ is the asymptote, $\mathrm{C}_{\min }$ is the size of the modeled pool that was mineralized and $r$ is the decay rate of the root exudate $\mathrm{C}\left(\mathrm{h}^{-1}\right)$. Curve fitting was performed in SigmaPlot 12.3 (Systat Software Inc., San Jose, CA). We justified the use of a single-pool model because the size of the modeled pool of mineralized root exudate $C(57 \pm 2.3 \%$ of total root exudate $\mathrm{C}$ added) did not vary significantly with management $(P=0.492)$. The half-life $\left(t_{1 / 2}\right)$ of this modeled pool was calculated as $\ln (2) / r$. 


\subsection{Bomb-spike ${ }^{14} \mathrm{C}$ turnover modeling}

Atmospheric nuclear weapons testing in the middle of the 20 th century nearly doubled the ${ }^{14} \mathrm{C}$ content of the atmosphere. When time series samples are available, this excess ${ }^{14} \mathrm{C}$ can be utilized as a highly sensitive tracer of carbon fluxes in terrestrial ecosystems (Trumbore, 1993; Baisden et al., 2013). Here, we have applied a steady-state soil carbon turnover model to estimate SOC turnover times $(\tau)$ in the five rotations. The model is nearly identical to the twopool model presented by Baisden et al. (2013) with the exception that inputs $\left(\mathrm{C}_{\mathrm{in}}\right)$ are partitioned into three pools (active, slow and passive) each with a characteristic decay rates ( $k_{\text {pool }}$, where $\left.\tau_{\text {pool }}=1 / k_{\text {pool }}\right)$. Carbon entering the soil each year will have the ${ }^{14} \mathrm{C} /{ }^{12} \mathrm{C}$ ratio of the previous year's atmospheric $\mathrm{CO}_{2}$. Inputs are then apportioned into the three pools in proportion to their fractional distribution $\left(f_{\text {pool }}\right)$ in the soil and losses are determined by first-order kinetics (i.e., $\left.k_{\text {pool }} \times C_{\text {pool }}\right)$ with shifts in ${ }^{14} \mathrm{C} /{ }^{12} \mathrm{C}$ ratio of each pool also effected by radioactive decay $\left(\lambda=1.21 \times 10^{-4} \mathrm{yr}^{-1}\right)$. Data for the Southern Hemisphere were taken from Currie et al. (2011). The overall SOC decay rate $\left(k_{\text {overall }}\right)$ was calculated as the pool weighted mean value and then the overall SOC turnover time ( $\left.\tau_{\text {overall }}\right)$ is the reciprocal of this value.

In this model there are five tuneable parameters: the decay constants $\left(k_{\text {pool }}\right)$ for the three pools and the fractional allocation of $C_{\text {in }}$ into the pools (given $f_{\text {active }}+f_{\text {slow }}+f_{\text {resistant }}$ must equal 1 , only two of the three pools can be solved for). In order to avoid overfitting, since we have only four observations per treatment, no more than three parameters could be solved for in any given scenario. We chose to take two complimentary approaches to fit the model. In the first scenario, we used the distribution of SOC into measurable fractions as determined by MIR-PLSR to fix the $f$ parameters and solved for the $k_{\text {pool }}$ values by minimizing the sum of squared errors between observed and predicted SOC $\Delta^{14} \mathrm{C}$ values. In the second scenario, the $k_{\text {pool values were fixed at }}$ $0.33,0.02$ and $0.001 \mathrm{yr}^{-1}$ for the active, slow and resistant pools and the model was solved for $f_{\text {active }}$ and $f_{\text {slow }}$. These $k_{\text {pool }}$ values were chosen because they are the default values in the Rothamsted Soil Carbon (RothC) model (Jenkinson, 1990) with the resistant pool being equivalent to that found in the CENTURY model (Parton et al., 1987).

Models were evaluated using root mean square error (RMSE) and standard error (SE) between measured $\left(y_{i}\right)$ and predicted $(y)$ values:

$\operatorname{RMSE}=\sqrt{\frac{\sum_{i=1}^{n}\left(y_{i}-\hat{y}\right)^{2}}{n}}$,

$\mathrm{SE}=\sqrt{\frac{\sum_{i=1}^{n}\left(y_{i}-\hat{y}-\mathrm{Bias}\right)^{2}}{n-1}}$

, where

$\operatorname{Bias}=\frac{\sum_{i=1}^{n}\left(y_{i}-\hat{y}\right)}{n}$.
Lastly, because the SOC stocks are known, the annual heterotrophic respiration $\left(R_{\mathrm{h}}=S O C / \tau\right)$ can be calculated and compared to estimates of $C_{\text {in }}$ as an independent check on the reality of the model because, at steady state, inputs should equal losses. Carbon inputs $\left(C_{i n}\right)$ to the upper $10 \mathrm{~cm}$ were estimated using measured aboveground dry matter production (DM) and yield (Yield) data as follows:

$\mathrm{C}_{\mathrm{in}}=\mathrm{C}_{\mathrm{dm}} \times\left[(\mathrm{DM}-\right.$ Yield $) \times$ StubRet $\left.+\mathrm{DM} \times \mathrm{RtS} \times F_{\text {root }}\right]$,

where $C_{d m}$ is the carbon content of plant residues estimated as $450 \mathrm{mg} \mathrm{Cg}^{-1}$; StubRet is the stubble retention factor, which was set to 0.40 for both crops and pasture phases based on agronomic records (Grace et al., 1995); RtS is the root-to-shoot ratio, which was set to 0.40 for wheat and oats and to 0.55 for pasture as adopted in the Australian National GHG Accounting system (Skjemstad et al., 2004); and $F_{\text {root }}$ is the fraction of total root biomass found in the upper $10 \mathrm{~cm}$, which was estimated at 0.65 for crops and 0.63 for improved pastures based on root biomass distribution data of similar varieties in similar soil conditions (Siddique et al., 1990; Lodge and Murphy, 2006).

\subsection{Data analysis}

One-way repeated-measures analysis of variance (ANOVA) tests with year as subject and rotation as factor were used to determine whether significant differences existed between the different rotations for carbon stocks, fractional distribution, amino sugar yields and short-term availability/activity measurements using SigmaPlot 12.3 (Systat Software Inc., San Jose, CA). Pairwise multiple comparisons were performed using the conservative Holms-Sidak method $(\alpha=$ $0.05)$. Aboveground dry matter production and soil carbon input data were normalized using square root or square root $(Y+1)$ transformations when fallows were excluded or included, respectively, prior to testing for significant differences between mean annual data for 1963-1993 time period using a one-way ANOVA for the factor rotation.

\section{Results}

Mean annual dry matter production varied from 2.0 to 9.6 $\mathrm{MgDM} \mathrm{ha}{ }^{-1} \mathrm{yr}^{-1}$ and mean $\mathrm{C}_{\text {in }}$ varied from 0.48 to 3.24 Mg C ha ${ }^{-1} \mathrm{yr}^{-1}$ from WF to Pa rotations (Table 1) with most of the within treatment variability between 1963 and 1993 being due to differences in annual rainfall (Fig. 1a). Grain yield trends are discussed in detail in Grace et al. (1995) and are not shown here. By 1963, most of the change in SOC stocks had occurred (at the commencement of the trial in 1925, Grace et al., 1995, estimated that the top $10 \mathrm{~cm}$ contained $2.75 \% \mathrm{C}$, equating to $34.2 \mathrm{Mg} \mathrm{Cha}^{-1}$ using the BD pedotransfer function presented in Fig. 1) with the exception of the WOF treatment where stocks showed a near-significant $(P=0.08)$ negative linear trend with time 


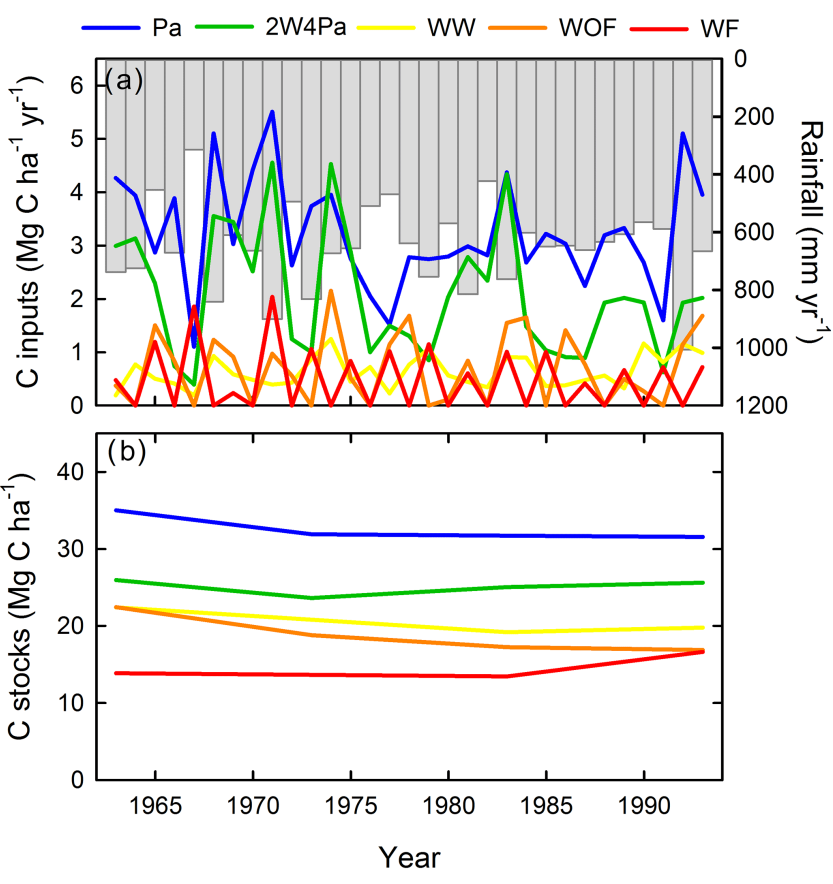

Figure 1. Annual precipitation and carbon inputs for the five cropping systems (a), and measured soil organic carbon stocks to $10 \mathrm{~cm}$ at the four sampling dates in these cropping systems (b). Cropping systems are as follows: $\mathrm{Pa}$, permanent pasture; $2 \mathrm{~W} 4 \mathrm{~Pa}, 2$ years of wheat followed by 4 years of pasture; WW, continuous wheat; WOF, wheat-oat-fallow rotation; WF, wheat-fallow rotation.

between 1963 and 1993 (Fig. 1b). Averaged across this period, SOC stocks ranged from 14.4 to $32.6 \mathrm{Mg} \mathrm{Cha}^{-1}$ in the same general order of increasing treatment production (Table 2). The $\mathrm{C}: \mathrm{N}$ ratio of the bulk SOM was slightly but significantly lower in the treatments with pasture phases relative to the treatments without pastures (Table 2). Particulate OC stocks varied from 1.0 to $5.5 \mathrm{Mg} \mathrm{Cha}^{-1}$ across the treatments resulting in a doubling of the proportional distribution of SOC into POC versus HOC + ROC fractions (Table 2).

Solid-state ${ }^{13} \mathrm{C}$ NMR spectra normalized to the amount of observable $\mathrm{C}$ in the measured sample also suggested more active cycling carbon in the treatments with pasture phases (Fig. 2). All treatments had a similar amount of aryl (110$145 \mathrm{ppm})$ and O-aryl C (145-165 ppm) but there were increasing amounts of alkyl (0-45 ppm), N-alkyl (45-60 ppm) and O-alkyl C (60-95 ppm) with increasing productivity. The alkyl to $\mathrm{O}$-alkyl $\mathrm{C}$ ratio, indicative of the degree of microbial processing of OM (Baldock et al., 1997), decreased with increasing productivity and SOC content, suggesting less microbially processed $\mathrm{OM}$ in the high-productivity treatments (Fig. 2 inset).

The yield of total amino sugars was significantly $(P=0.009)$ impacted by the rotation, with the permanent pasture having significant more amino sugars per gram of soil than most other rotations (Table 3). This trend was
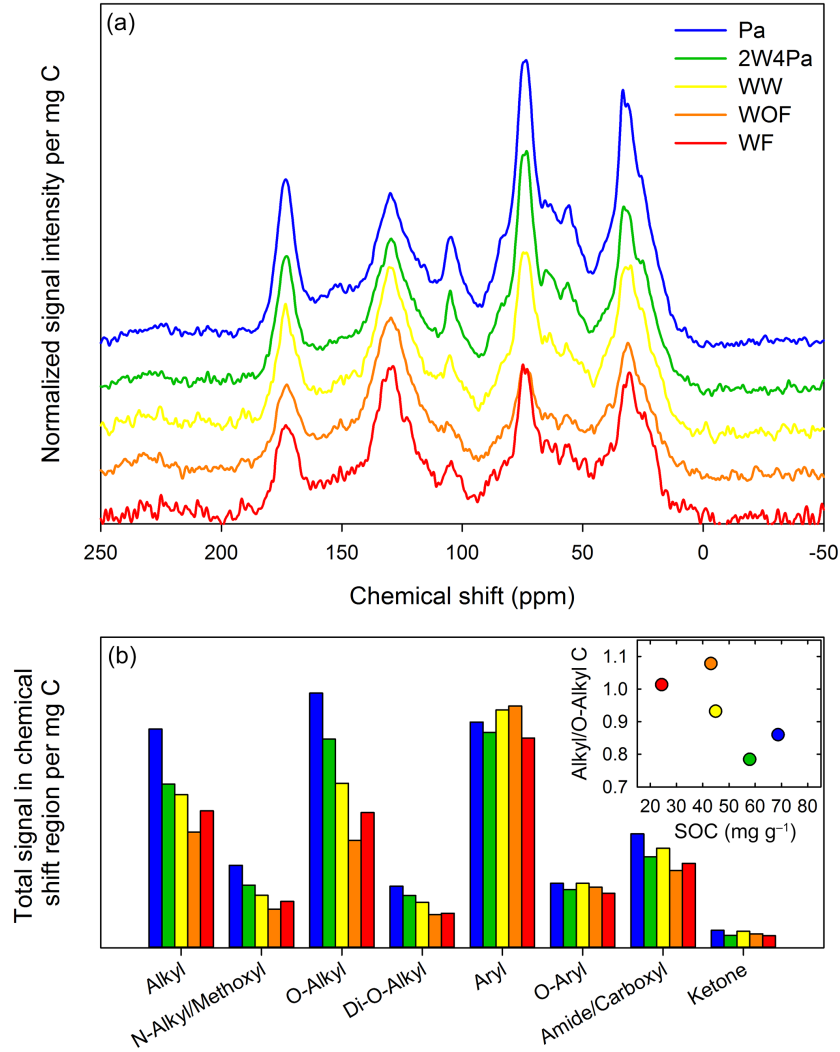

Figure 2. Solid-state ${ }^{13} \mathrm{C}$ NMR spectra (a) and total signal intensity integrated into eight major chemical shift regions (b) for the 1983 soil samples from the five treatments. Signal intensity has been normalized for number of scans, nc_proc, $\mathrm{C}$ observability and C content in NMR rotor ( $y$ axis units are irrelevant). Inset in (b) shows the alkyl $\mathrm{C}$ to O-alkyl $\mathrm{C}$ ratio plotted as a function of SOC content $\left(R^{2}=0.51, P=0.17\right)$.

present in every amino sugar (glucosamine $P=0.008$; galactosamine $P=0.012$, muramic acid $P=0.008$ ) except mannosamine $(P=0.70)$. There were significant positive linear trends between individual and total amino sugar yields and SOC stocks for all sugars except mannosamine (data not shown).

The degree of uptake of the bomb spike in atmospheric ${ }^{14} \mathrm{CO}_{2}$ into the soil also followed an increasing trend with increasing productivity with the exception that the WOF treatment had more negative $\Delta^{14} \mathrm{C}$ values than the WF treatment in all years except 1963 (Fig. 3). Both modeling scenarios provided good representations of the $\Delta^{14} \mathrm{C}$ data (Figs. 3, C1) with scenario 1 ( $k_{\text {pool }}$ values solved for while allocations to pools were fixed using estimates from MIR-PLSR) performing slightly better (Table 4). In scenario 1 , the turnover time $(\tau)$ for each pool decreased along the treatment productivity gradient (Fig. 4a). In scenario 2 with fixed $k_{\text {pool }}$ values, the proportion of SOC allocated to the active and slow cycling pools generally increased while the allocation to the resistant pool decreased with increasing productivity (Fig. 4c), 
Table 1. Mean and standard deviation of annual treatment production and soil C input data during 1963-1993. Significant differences (one-way ANOVA, $\alpha<0.05$ ) between rotations are indicated with different letters in each column.

\begin{tabular}{|c|c|c|c|c|}
\hline \multirow[b]{2}{*}{ Rotation } & \multicolumn{2}{|c|}{ Dry matter $\left(\mathrm{Mg} \mathrm{DM} \mathrm{ha}^{-1}\right)$} & \multicolumn{2}{|c|}{$\mathrm{C}$ inputs $\left(\mathrm{Mg} \mathrm{Cha}^{-1}\right)$} \\
\hline & Annual mean ${ }^{1,2}$ & Cumulative & Annual mean ${ }^{1,2}$ & Cumulative \\
\hline $\mathrm{Pa}$ & $9.63 \pm 3.11^{\mathrm{a}}$ & 298.63 & $3.24 \pm 1.05^{\mathrm{a}}$ & 100.32 \\
\hline $2 \mathrm{~W} 4 \mathrm{~Pa}$ & $6.49 \pm 3.28^{b}$ & 201.10 & $2.07 \pm 1.17^{\mathrm{b}}$ & 64.23 \\
\hline WW & $2.66 \pm 1.28^{\mathrm{c}, \mathrm{d}}$ & 82.52 & $0.63 \pm 0.30^{c}$ & 19.66 \\
\hline WOF & $3.10 \pm 2.81^{\mathrm{c}}$ & 96.01 & $0.70 \pm 0.67^{\mathrm{c}}$ & 21.84 \\
\hline WF & $2.02 \pm 2.31^{\mathrm{d}}$ & 62.76 & $0.48 \pm 0.59^{\mathrm{c}}$ & 15.02 \\
\hline
\end{tabular}

1 Annual mean includes a value of 0 for fallow years. ${ }^{2}$ Data transformed using square root (value +1$)$ for ANOVA.

Table 2. Soil carbon data summary. Mean across time and standard deviation given for each rotation. Significant differences (one-way repeated-measures ANOVA, $\alpha<0.05$ ) between rotations are indicated with different letters in each column.

\begin{tabular}{|c|c|c|c|c|c|c|c|c|c|}
\hline \multirow[b]{2}{*}{ Rotation $^{\mathrm{a}}$} & \multicolumn{2}{|c|}{ Measured } & \multicolumn{6}{|c|}{ MIR-PLSR predicted data } & \multirow{2}{*}{$\frac{\Delta^{14} \mathrm{C} \text { value }}{\text { SOC }}$} \\
\hline & SOC & $\mathrm{C}: \mathrm{N}$ & POC $^{\mathrm{b}}$ & $\mathrm{HOC}^{\mathrm{b}}$ & $\mathrm{ROC}^{\mathrm{b}}$ & $f(\mathrm{POC})^{\mathrm{c}}$ & $f(\mathrm{HOC})^{\mathrm{c}}$ & $f(\mathrm{ROC})^{\mathrm{c}}$ & \\
\hline & \multicolumn{2}{|c|}{$\left(\mathrm{MgCha}^{-1}\right)$} & & $\left(\mathrm{MgCha}^{-1}\right)$ & & & & & $(\% o)$ \\
\hline $\mathrm{Pa}$ & $32.6 \pm 1.6^{\mathrm{a}}$ & $10.9 \pm 0.4^{\mathrm{a}}$ & $5.2 \pm 0.7^{\mathrm{a}}$ & $17.8 \pm 0.7^{\mathrm{a}}$ & $9.4 \pm 0.7^{\mathrm{a}}$ & $0.16 \pm .01^{\mathrm{a}}$ & $0.55 \pm .01^{\mathrm{a}}$ & $0.29 \pm .01^{\mathrm{a}}$ & $90.8 \pm 51.7^{\mathrm{a}}$ \\
\hline $2 \mathrm{~W} 4 \mathrm{~Pa}$ & $25.1 \pm 1.0^{\mathrm{b}}$ & $10.9 \pm 0.3^{\mathrm{a}}$ & $2.8 \pm 0.3^{\mathrm{b}}$ & $14.4 \pm 0.5^{\mathrm{b}}$ & $8.0 \pm 0.5^{\mathrm{b}}$ & $0.11 \pm .01^{\mathrm{b}}$ & $0.57 \pm .01^{\mathrm{b}}$ & $0.32 \pm .01^{\mathrm{b}}$ & $59.1 \pm 63.8^{\mathrm{a}, \mathrm{b}}$ \\
\hline WW & $20.6 \pm 1.4^{\mathrm{c}}$ & $11.9 \pm 0.3^{\mathrm{b}}$ & $1.9 \pm 0.2^{\mathrm{b}}$ & $11.9 \pm 0.8^{b}$ & $6.6 \pm 0.6^{\mathrm{b}, \mathrm{c}}$ & $0.09 \pm .01^{\mathrm{b}}$ & $0.58 \pm .00^{\mathrm{b}, \mathrm{c}}$ & $0.32 \pm .01^{\mathrm{b}, \mathrm{c}}$ & $22.7 \pm 44.3^{\mathrm{b}, \mathrm{c}}$ \\
\hline WOF & $18.8 \pm 2.5^{\mathrm{d}}$ & $11.7 \pm 0.3^{\mathrm{a}, \mathrm{b}}$ & $1.3 \pm 0.3^{\mathrm{c}}$ & $11.0 \pm 1.5^{\mathrm{c}}$ & $6.5 \pm 0.8^{\mathrm{c}}$ & $0.07 \pm .01^{\mathrm{c}}$ & $0.58 \pm .01^{\mathrm{b}, \mathrm{c}}$ & $0.35 \pm .01^{\mathrm{c}}$ & $-27.4 \pm 24.8^{\mathrm{c}}$ \\
\hline WF & $14.4 \pm 1.5^{\mathrm{e}}$ & $12.1 \pm 0.7^{\mathrm{b}}$ & $1.1 \pm 0.3^{\mathrm{c}}$ & $8.6 \pm 0.7^{d}$ & $4.8 \pm 0.5^{\mathrm{d}}$ & $0.07 \pm .01^{\mathrm{c}}$ & $0.60 \pm .01^{\mathrm{c}}$ & $0.33 \pm .01^{\mathrm{b}, \mathrm{c}}$ & $-2.2 \pm 50.0^{\mathrm{c}}$ \\
\hline
\end{tabular}

${ }^{a} \mathrm{~Pa}$, permanent pasture; 2W4Pa, 2 years of wheat followed by 4 years of pasture; WW, continuous wheat; WOF, wheat-oat-fallow rotation; WF, wheat-fallow rotation. ${ }^{\mathrm{b}}$ POC, particulate organic carbon; HOC, humic organic carbon; ROC, resistant organic carbon. ${ }^{c}$ Fraction as a proportion of bulk soil carbon.

although these changes were overestimated relative to actual fraction distributions (Table 2). In both scenarios this resulted in a decrease in $\tau_{\text {overall }}$ from $40-30$ to $13-8$ years (Fig. $4 \mathrm{c}$, d).

To complement the long-term integrative data presented above using $\Delta^{14} \mathrm{C}$, assays pertinent to short-term $\mathrm{C}$ cycling were also conducted (Table 5). In general, trends in absolute (per gram of soil) terms followed the long-term integrative data, in that $\mathrm{Pa}$ had the greatest amount of extractable $\mathrm{C}$, the highest basal respiration rate, and the fastest turnover (shortest $t_{1 / 2}$ ) of respired root exudate $\mathrm{C}$, whereas the reverse was observed for WF. Other rotations were intermediate.

\section{Discussion}

Globally, there are ever increasing demands on soils to meet growing food demand on a finite land area. Simultaneously, there is a recognition that gains in agricultural production cannot continue to come simply by mining the soil resource. Given the additional desire to offset agriculture's GHG footprint, management that promotes the regeneration of SOM is now a high priority on many nations' research, development and extension agendas (Bustamante et al., 2014). However, there is debate as to whether soils can simultaneously mitigate climate change through carbon sequestration and provide the nutrition needed for increased crop production

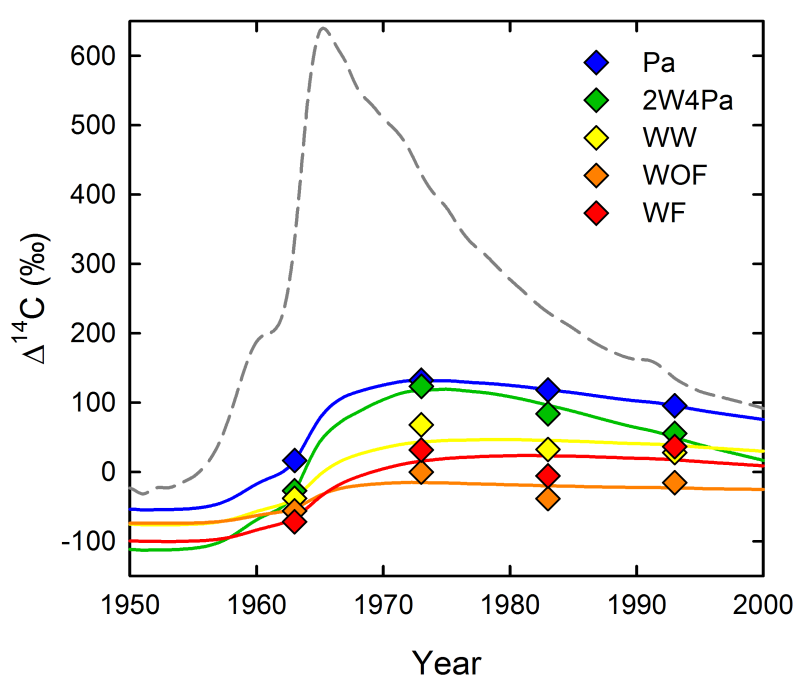

Figure 3. $\Delta^{14} \mathrm{C}$ values of soil organic carbon in upper $10 \mathrm{~cm}$ along with yearly output from the best-fit bomb-spike model solutions for scenario 1 (curve fits for scenario 2 shown in Fig. C1 in Appendix C) where the allocation of $\mathrm{C}$ to pools was fixed using the estimated fractions from MIR-PLSR analysis and the model was solved for $k$ values. Southern Hemisphere atmospheric ${ }^{14} \mathrm{CO}_{2}$ record is shown for reference (dashed line). 
Table 3. Amino sugar data (mean \pm 1 SD reported). One-way repeated-measures ANOVA summary given below each data column and pairwise comparisons between rotations are indicated with different letters in each column when significant $(\alpha<0.05)$.

\begin{tabular}{|c|c|c|c|c|c|}
\hline Rotation & \multicolumn{5}{|c|}{$\left(\mathrm{mg}\right.$ amino sugar g soil $\left.{ }^{-1}\right)$} \\
\hline $\mathrm{Pa}$ & $0.84 \pm 0.18^{\mathrm{a}}$ & $0.022 \pm 0.017$ & $0.32 \pm 0.08^{\mathrm{a}}$ & $0.059 \pm 0.016^{\mathrm{a}}$ & $1.24 \pm 0.30^{\mathrm{a}}$ \\
\hline $2 \mathrm{~W} 4 \mathrm{~Pa}$ & $0.47 \pm 0.34^{\mathrm{a}, \mathrm{b}}$ & $0.016 \pm 0.013$ & $0.14 \pm 0.12^{\mathrm{a}, \mathrm{b}}$ & $0.026 \pm 0.032^{b}$ & $0.66 \pm 0.50^{\mathrm{a}, \mathrm{b}}$ \\
\hline $\mathrm{W}$ & $0.32 \pm 0.22^{\mathrm{b}}$ & $0.021 \pm 0.025$ & $0.11 \pm 0.06^{\mathrm{b}}$ & $0.026 \pm 0.013^{b}$ & $0.48 \pm 0.31^{b}$ \\
\hline WOF & $0.27 \pm 0.10^{\mathrm{b}}$ & $0.008 \pm 0.002$ & $0.10 \pm 0.04^{\mathrm{b}}$ & $0.015 \pm 0.006^{\mathrm{b}}$ & $0.40 \pm 0.17^{b}$ \\
\hline WF & $0.42 \pm 0.14^{\mathrm{a}, \mathrm{b}}$ & $0.012 \pm 0.001$ & $0.15 \pm 0.04^{\mathrm{a}, \mathrm{b}}$ & $0.029 \pm 0.018^{\mathrm{a}, \mathrm{b}}$ & $0.63 \pm 0.22^{\mathrm{a}, \mathrm{b}}$ \\
\hline$P$ value & 0.008 & 0.700 & 0.012 & 0.008 & 0.009 \\
\hline
\end{tabular}

Table 4. Turnover model goodness-of-fit statistics.

\begin{tabular}{|c|c|c|c|c|c|c|}
\hline \multirow[b]{2}{*}{ Rotation } & \multicolumn{3}{|c|}{ Scenario 1: fit $k$ with $f$ fixed } & \multicolumn{3}{|c|}{ Scenario 2: fit $f$ with $k$ fixed } \\
\hline & $\mathrm{RMSE}^{\mathrm{a}}$ & $\mathrm{SE}^{\mathrm{b}}$ & $R_{\mathrm{h}}^{\mathrm{c}}$ & $\mathrm{RMSE}^{\mathrm{a}}$ & $\mathrm{SE}^{\mathrm{b}}$ & $R_{\mathrm{h}}^{\mathrm{c}}$ \\
\hline $\mathrm{Pa}$ & 0.25 & 0.29 & 3.35 & 4.74 & 5.39 & 2.45 \\
\hline $2 \mathrm{~W} 4 \mathrm{~Pa}$ & 7.63 & 8.81 & 3.18 & 21.08 & 23.91 & 1.78 \\
\hline WW & 15.08 & 17.42 & 0.95 & 12.26 & 13.95 & 1.20 \\
\hline WOF & 12.61 & 14.56 & 0.47 & 11.93 & 13.78 & 0.66 \\
\hline WF & 19.35 & 22.34 & 0.43 & 23.48 & 26.88 & 0.29 \\
\hline
\end{tabular}

${ }^{a}$ RMSE, root mean square error. ${ }^{\mathrm{b}} \mathrm{SE}$, standard error. ${ }^{\mathrm{c}} R_{\mathrm{h}}$, steady-state heterotrophic respiration $\left(\mathrm{tCha}^{-1} \mathrm{yr}^{-1}\right)$.

(Janzen, 2006). The Waite trial data demonstrate that a higher carbon return management strategy can provide both of these benefits as the results indicate significantly increased soil microbial activity and greater SOC stocks.

After nearly 70 years under consistent management representing a 5-fold gradient in plant productivity (Table 1), a gradient in SOC stocks ranging from 14 to $33 \mathrm{Mg} \mathrm{Cha}^{-1}$ was established. It is important to acknowledge here that the range of observed SOC stocks was a result of greater SOC losses in the low-productivity treatments relative to the 1925 initial stocks, with most of this loss occurring between 1925 and 1963 (Grace et al., 1995). The leveling-off in the loss rates suggests that these treatments were close to a steadystate SOC value with respect to the long-term management. The strong linear relationship between inputs and SOC is well supported by findings in other agricultural trials (e.g., Rasmussen and Parton, 1994; Paustian et al., 1997; Kong et al., 2005) and forms one of the principle tenets of most conceptual (Jenny, 1941) and numerical models of SOC dynamics (e.g., Parton et al., 1987; Jenkinson 1990).

There were strong correlations between nearly all of the measured, estimated and modeled parameters (Table 6). With increasing annual $\mathrm{C}$ inputs, a greater proportion of SOC in what is regarded as a readily available form (i.e., POC) was found. A more nuanced picture emerges from interpretation of the NMR data (Fig. 2a); by normalizing the NMR spectra to observable $\mathrm{C}$ content, all treatments appear to have a similar amount of char-like carbon (peak centered at $130 \mathrm{ppm}$ ) but increasing amounts of both plant (i.e., POClike, high fraction of O-alkyl C) and microbial-like (i.e., highly aliphatic compounds, alkyl and $\mathrm{N}$-alkyl C) OM with increasing productivity, agreeing with the $\mathrm{C}$ fractionation data. The amino sugar results lend further support for increasing amounts of microbially derived OM in the soils under the higher input rotations. Modeling scenario 2 supported this notion as well with an increase in proportion of SOC in the active and slow cycling pools at the expense of the resistant pool (Fig. 4c). These findings, again, are consistent with expectations from previous research across a range of ecosystems (e.g., Cambardella and Elliot, 1992; Kong et al., 2005; Lajtha et al., 2014) and would be more or less simulated by most multiple-pool numerical models. For example, Kong et al. (2005) found a $5 \mathrm{Mg} \mathrm{Cha}^{-1}$ gradient in POC, measured as the $250-2000 \mu \mathrm{m}$ size fraction, after 10 years under a range of management practices resulting in a tenfold gradient in C inputs.

The striking and unexpected feature of this analysis was the 3-fold increase in carbon cycling rates $\left(k_{\text {overall }}\right)$ with increasing productivity revealed by modeling the incorporation of the bomb spike in atmospheric ${ }^{14} \mathrm{CO}_{2}$. We used the term "unexpected" because this rate of increase in carbon cycling was much greater than would be predicted from simple steady-state or pool distribution considerations (Fig. 5). The most basic way to estimate $k_{\text {overall }}$ would be to assume a sin- 


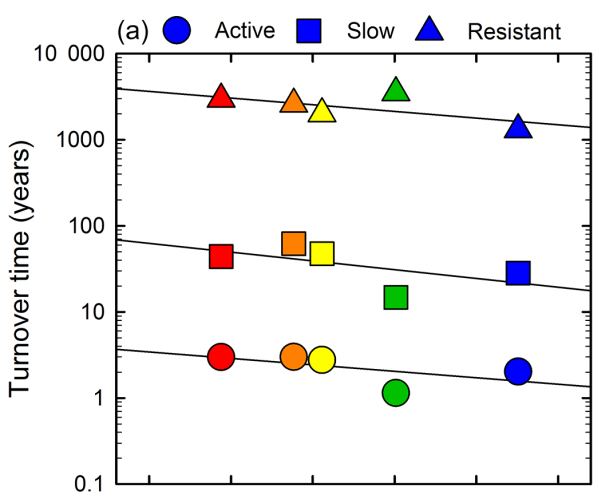

(b) Overall rate

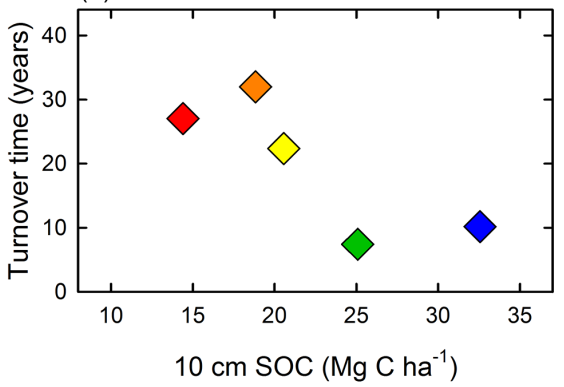

(c)

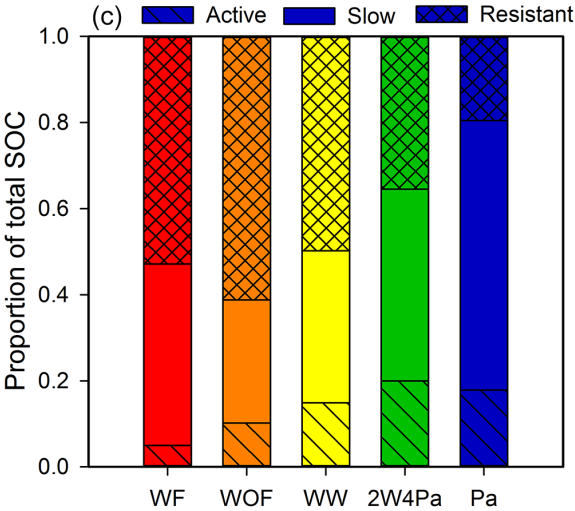

(d) Overall rate

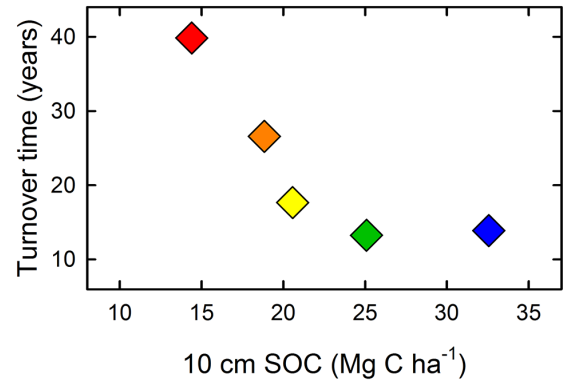

Figure 4. Turnover time for soil organic carbon (SOC) pools (a) and inventory-weighted SOC turnover time (b) for best-fit model solutions when allocation of $\mathrm{C}$ to fractions from MIR-PLSR predictions was used (scenario 1). In (c), best-fit model solutions for allocation of SOC to pools when turnover times were fixed at 3, 50 and 1000 years for active, slow and resistant pools, respectively (scenario 2), with the inventory-weighted overall turnover time given in (d). Colors representing the five treatment sites as in Fig. 1.

Table 5. Short-term microbiological activity assays (mean of sampling times \pm 1 SD reported). One-way repeated-measures ANOVA summary given below each data column and pairwise comparisons between rotations are indicated with different letters in each column when significant $(\alpha<0.05)$.

\begin{tabular}{lrrrrr}
\hline & & & \multicolumn{2}{c}{ Root exudate curve fit parameters } \\
\cline { 3 - 6 } Rotation & Extractable OC & $\begin{array}{r}\text { Basal } \\
\text { respiration }\end{array}$ & $\begin{array}{r}\text { Size of } \\
\left(\mu \mathrm{mol} \mathrm{CO}_{2} \mathrm{~d}^{-1}\right)\end{array}$ & $\begin{array}{r}\text { Decay rate } \\
\text { of pool } \\
\left(\mathrm{h}^{-1}\right)\end{array}$ & $\begin{array}{r}\text { Half-life } \\
\text { of pool } \\
(\mathrm{h})\end{array}$ \\
\hline $\mathrm{Pa}$ & $207 \pm 26^{\mathrm{a}}$ & $7.1 \pm 0.4^{\mathrm{a}}$ & $57.2 \pm 3.2$ & $0.033 \pm .005^{\mathrm{a}}$ & $21.5 \pm 3.0^{\mathrm{a}}$ \\
$\mathrm{W} 4 \mathrm{PA}$ & $132 \pm 22^{\mathrm{b}}$ & $5.6 \pm 0.6^{\mathrm{a}}$ & $55.8 \pm 2.0$ & $0.029 \pm .006^{\mathrm{a}, \mathrm{b}}$ & $24.4 \pm 4.0^{\mathrm{a}, \mathrm{b}}$ \\
$\mathrm{WW}$ & $67 \pm 7.1^{\mathrm{c}}$ & $3.5 \pm 0.2^{\mathrm{b}}$ & $56.6 \pm 2.8$ & $0.027 \pm .005^{\mathrm{a}, \mathrm{b}}$ & $26.5 \pm 4.8^{\mathrm{a}, \mathrm{b}}$ \\
$\mathrm{WOF}$ & $64 \pm 12^{\mathrm{c}}$ & $3.4 \pm 0.4^{\mathrm{b}}$ & $56.6 \pm 0.6$ & $0.026 \pm .002^{\mathrm{b}}$ & $27.3 \pm 2.4^{\mathrm{a}, \mathrm{b}}$ \\
$\mathrm{WF}$ & $55 \pm 22^{\mathrm{a}}$ & $3.1 \pm 0.6^{\mathrm{b}}$ & $58.8 \pm 2.2$ & $0.023 \pm .003^{\mathrm{b}}$ & $30.4 \pm 4.4^{\mathrm{b}}$ \\
\hline$P$ value & $<0.001$ & $<0.001$ & 0.227 & 0.004 & 0.009 \\
\hline
\end{tabular}

gle homogenous pool at steady state so $k_{\text {overall }}=\mathrm{C}_{\text {in }} / \mathrm{SOC}$. This calculation suggests $k_{\text {overall }}$ increases $75 \%$ from the low to high productivity systems (Fig. 5). Another method is to assume that each fraction has a characteristic $k$ (as in CENTURY or RothC), and with the estimated distribution of $\mathrm{C}$ into fractions from the MIR-PLSR analysis (Table 2), $k_{\text {overall }}$ similarly increases by $75 \%$ with increasing productivity. However, the $k_{\text {overall }}$ determined from the more robust ${ }^{14} \mathrm{C}$ modeling increased $300 \%$ from low to high productiv- ity (Fig. 5). Importantly, the increase in $k_{\text {overall }}$ with increasing productivity could not be explained by the RothC model (Sanderman et al., 2016). Sanderman et al. (2016) found that the decay constants in RothC needed to be adjusted in a similar manner as seen in Fig. 4a in order to explain the SOC and ${ }^{14} \mathrm{C}$ data across the five treatments.

While the Waite trial represented a large productivity gradient, the quality of the incoming organic matter was not equal. The treatments with pasture phases contained N-fixing 
Table 6. Pearson's correlation coefficients between mean annual $\mathrm{C}$ input $\left(\mathrm{C}_{\mathrm{in}}\right), \mathrm{SOC}$ stock, $\mathrm{C}: \mathrm{N}$ ratio, fraction of SOC as POC $\left(f_{\mathrm{POC}}\right)$, radiocarbon activity $\left(\Delta^{14} \mathrm{C}\right.$ ), overall turnover time (given as the average of the two modeling scenarios, $\tau_{\text {mean }}$ ), half-life of added root exudates cocktail $\left(t_{1 / 2}\right)$, the alkyl / O-alkyl C ratio from NMR data (A / O-A), and the total yield of amino sugars $\left(\sum A S\right)$.

\begin{tabular}{lrrrrrrrr}
\hline & SOC & $\mathrm{C}: \mathrm{N}$ & $f_{\mathrm{POC}}$ & $\mathrm{A} / \mathrm{O}-\mathrm{A}$ & $\sum \mathrm{AS}$ & $\Delta^{14} \mathrm{C}$ & $\tau_{\text {mean }}$ & $t_{1 / 2}$ \\
\hline $\mathrm{C}_{\text {in }}$ & $0.93^{* *}$ & $-0.94^{* *}$ & $0.95^{* *}$ & -0.72 & $0.87^{*}$ & $0.90^{* *}$ & $-0.83^{*}$ & $-0.94^{* *}$ \\
$\mathrm{SOC}$ & & $-0.83^{*}$ & $0.96^{* *}$ & -0.67 & 0.80 & $0.87^{*}$ & $-0.86^{*}$ & $-0.99^{* *}$ \\
$\mathrm{C}: \mathrm{N}$ & & & $-0.81^{*}$ & 0.76 & -0.67 & $-0.80^{*}$ & $0.86^{*}$ & $0.90^{* *}$ \\
$f_{\mathrm{POC}}$ & & & & -0.72 & $0.91^{* *}$ & $0.95^{* *}$ & $-0.83^{*}$ & $-0.93^{* *}$ \\
$\mathrm{~A} / \mathrm{O}-\mathrm{A}$ & & & & & -0.54 & $-0.89^{* *}$ & $0.93^{* *}$ & 0.71 \\
$\sum_{\mathrm{AS}}$ & & & & & & $0.85^{*}$ & -0.57 & -0.74 \\
$\Delta^{14} \mathrm{C}$ & & & & & & & $-0.89^{* *}$ & $-0.86^{*}$ \\
$\tau_{\text {mean }}$ & & & & & & & & $0.90^{* *}$ \\
\hline
\end{tabular}

Significance $(n=5):{ }^{*} P<0.10,{ }^{* *} P<0.05$.

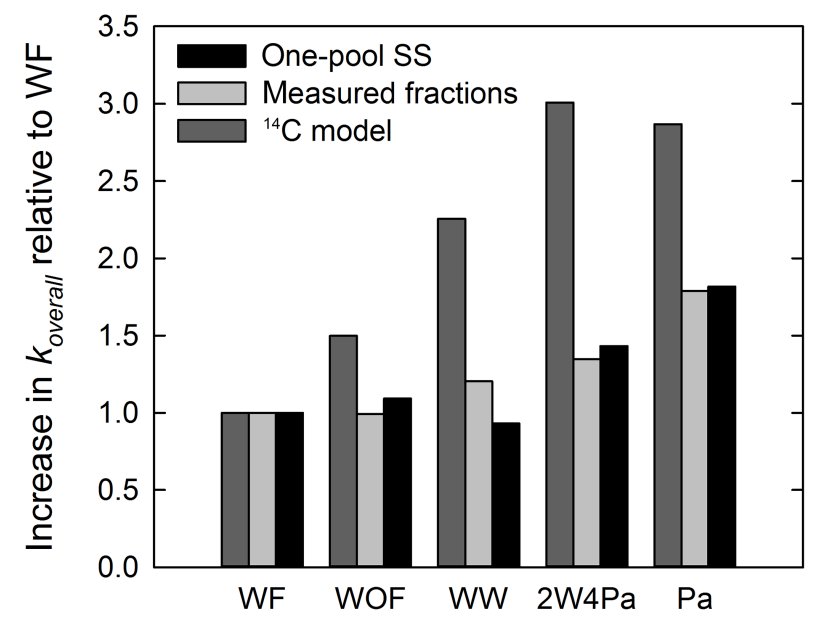

Figure 5. Comparison of different approaches for estimating changes in carbon cycling rates. Increases in $k_{\text {overall }}$ relative to the WF treatment is given for a simple one-pool steady-state (SS) calculation ( $k=\mathrm{C}_{\mathrm{in}} / \mathrm{SOC}$ ), the predicted $k$ based on measured fractions assuming $k_{\text {pool }}=0.33,0.02$ and $0.001 \mathrm{yr}^{-1}$ in the POC, HOC and ROC fraction, respectively, and the mean $k_{\text {overall value from mod- }}$ eling the incorporation of ${ }^{14} \mathrm{C}$ into the soil (scenario 1).

legumes (on average $26 \%$ of the pasture production was attributable to legumes based on pasture composition data included in the public data repository) which likely resulted in a more $\mathrm{N}$-rich input material. The bulk soil $\mathrm{C}: \mathrm{N}$ ratio was significantly lower in the two pasture treatments compared to the cropping rotations (Table 2). By providing more $\mathrm{N}$ to a likely N-limited system (no nitrogenous fertilizer was used in the trial), input quality may have acted in concert with increased inputs to further increase the SOC cycling rates seen in the $\mathrm{Pa}$ and $2 \mathrm{~W} 4 \mathrm{~Pa}$ treatments (Fig. 4b). However, higherquality (i.e., lower $\mathrm{C}: \mathrm{N}$ ) litter will also likely be used more efficiently by the microbial community thus potentially stabilizing more of this litter as SOC (Lange et al., 2015).
Although long- and short-term $\mathrm{C}$ turnover rates were well correlated with $\mathrm{C}_{\text {in }}$ and SOC stocks, the mechanisms behind the observed increases in both $\mathrm{C}$ stocks and overall decomposition rates $\left(k_{\text {overall }}\right)$ are not clear. Increased $\mathrm{C}$ inputs frequently increase the size and the activity of the soil microbial community and can result in the accelerated decomposition or "priming" of more stable, nutrient rich SOM (Fontaine et al., 2004; Dijkstra and Cheng 2007; Blagodatskya and Kuzyakov, 2008). Given that microbial biomass is typically positively associated with SOC levels (Wardle et al., 1999), with higher $\mathrm{C}_{\text {in }}$ and $\mathrm{SOC}$ stocks, overall decomposition rates $\left(k_{\text {overall }}\right)$ would increase as long as decomposition rate per unit microbial biomass stayed constant (Manzoni and Porporato, 2009). However, in typical linear donor-control models (e.g., RothC), microbial biomass size is uncoupled from SOC decomposition, which renders any changes in microbial biomass size irrelevant for SOC turnover, and therefore (in the instance of increasing microbial biomass) potentially underestimates $k_{\text {overall }}$ (Fang et al., 2005). An emerging class of nonlinear soil carbon models (e.g., Allison et al., 2010) allows coupling between microbial biomass size and SOC turnover, effectively representing the relationship between biomass size and $k_{\text {overall, }}$ although the form of this relationship remains unclear. Our results indicate that this approach is required at the Waite trial soils to accurately model SOC dynamics, and should produce better projections of SOC in response to change in management. Similarly, Lange et al. (2015) postulated that with increasing plant diversity, SOC stocks increased because a larger microbial community was driving a more efficient transfer of SOC from a fast to slow cycling $\mathrm{C}$ pool which effectively decreased the overall turnover rate. Importantly, the acceleration in carbon cycling $\left(k_{\text {overall }}\right)$ seen in the Waite trial data was not greater than the size of the imbalance between inputs over losses; thus, we observed a gradient of higher SOC stocks with increasing productivity.

The modeling work presented here and in all of the references discussed above assumes a static land surface yet 
erosion and its associated $\mathrm{C}$ loss is known to be quantitatively important in agricultural settings (Van Oost et al., 2007; Chappell et al., 2015). Chappell et al. (2015) estimated that at the Waite trial erosional loss of SOC could account for approximately $10 \%$ of the annual $\mathrm{C}$ flux from the soil on decadal timescales with lower estimates for the treatments with pasture phases and higher estimates for those with fallows. While we have not attempted to account for soil redistribution in this study, our findings and conclusions would not change if we had because the short-term microbial assays are independent of any erosion and the amount of erosion that has occurred (estimated as 3.0-7.7 mm per decade from Chappell et al., 2015) would be included as a minor component of the apparent $C$ turnover rate for the upper $100 \mathrm{~mm}$ of soil using time series ${ }^{14} \mathrm{C}$ measurements. This minor component would be within error margins.

In contrast to paradigms underlying most ecosystem soil carbon models, the acceleration in microbial cycling may itself be leading to increased SOM stabilization rates, as microbial activity has been shown to contribute to SOM formation through the production of microbial biomass residues (i.e., necromass) (Miltner et al., 2012; Cotrufo et al., 2013). These residues can constitute a large proportion of the more stable slow cycling OM pool and persist much longer than plant necromass (Kiem and Kögel-Knaber, 2003; Liang and Balser, 2008). Yet, where enhanced rates of stabilization occur, we find they are matched by enhanced turnover of the SOM pool. The fate, formation and stabilization of microbial biomass have therefore been highlighted as a major unknown in advancing the scientific understanding of soil carbon stabilization and turnover (e.g., Allison et al., 2010; Weider et al., 2013). Our results, showing increased plant productivity along with higher $\mathrm{C}$ stocks, faster $\mathrm{C}$ turnover and a greater abundance of amino sugars, suggest, in line with the conclusions of Lange et al. (2015), that concurrent increases in plant inputs, microbial activity, and microbially derived carbon are important for building and maintaining adequate SOM levels.

It is important to consider that these findings pertain to a specific but widely distributed soil type under a Mediterranean climatic regime representative of only limited portions of the globe. Unless soil moisture becomes very limiting, there is little reason to doubt that the finding that microbial activity would be accelerated with increased plant inputs would not be broadly applicable to agricultural soils globally. Whether or not this acceleration in plant inputs and microbial activity results in greater soil carbon stocks and the importance of microbial-derived carbon to the soil carbon pool may depend upon and vary with the edaphic properties of a particular soil (Barré et al., 2014; Sanderman et al., 2014).

\section{Conclusions}

The data from the Waite trial portray a nuanced and dynamic picture whereby increasing carbon flow to the soil leads to greater SOC stocks, but because of feedbacks to the microbial community there can be an acceleration of SOM mineralization beyond what would be expected based on simple steady-state and carbon pool distribution shift arguments. These feedbacks have important implications for how soil carbon dynamics are represented in conceptual and numerical models. From an agronomic standpoint, a simple but important picture emerges whereby a higher carbon return management system, in the case of the Waite trial meaning a greater number of pasture phases and no fallows, results in a soil with more soil carbon that is also supplying more nutrients back to the crop.

\section{Data availability}

The full agronomic, production and climatic data and measured/predicted soil properties from selected trials can be downloaded free of charge from the CSIRO Data Access Portal (doi:10.4225/08/55E5165EC0D29). 


\section{Appendix A: Bulk density pedotransfer function}

Bulk density was not measured during the trial years of 1963-1993 but it was measured in detail in 1997 at all of the Waite trial plots (Baldock, 1998 - data available upon request from either J. Sanderman or J. Baldock), not just the five selected for this current study. Plots were split and two full profiles were collected in $10 \mathrm{~cm}$ increments. Here we use the data collected from the $0-10$ and $10-20 \mathrm{~cm}$ horizons to develop a relationship between bulk density and percent organic carbon which is then applied to the soil samples collected in prior years.

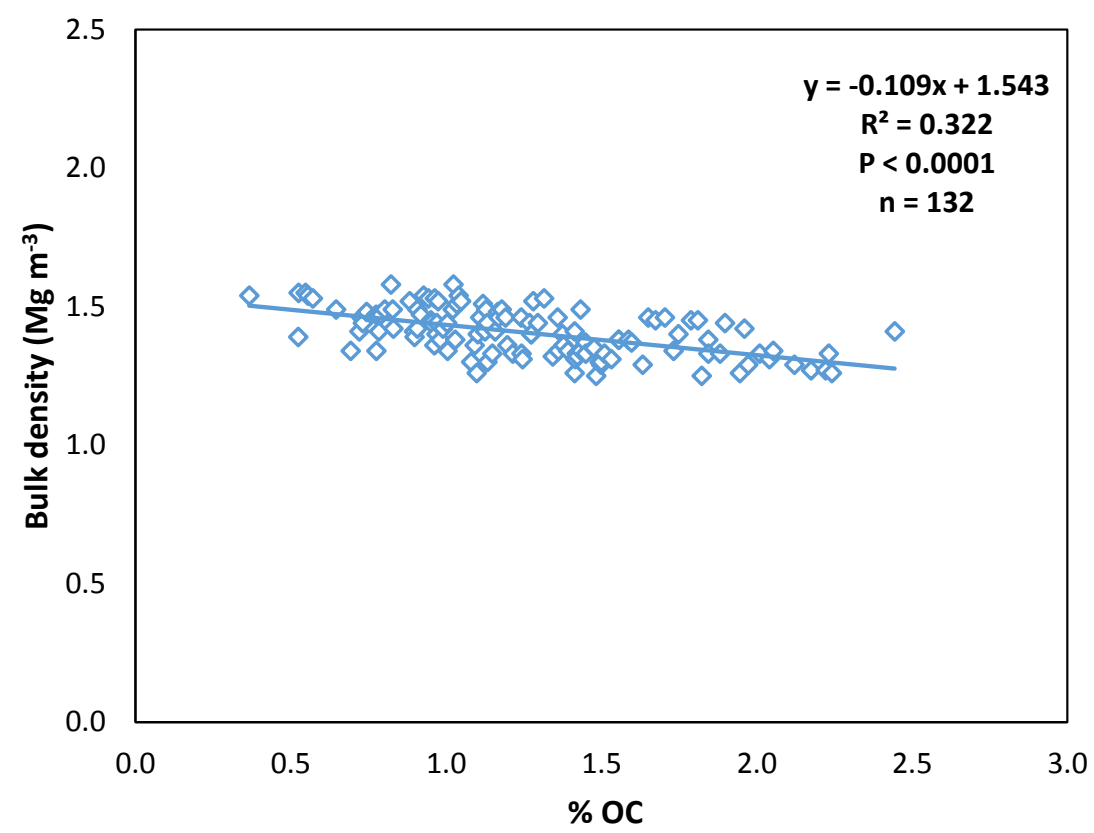

Figure A1. Relationship between organic carbon content (\%OC) and bulk density for the 0-10 and 10-20 cm soil layers collected in 1997 from all trial plots. 
Appendix B: Root exudate decay curves

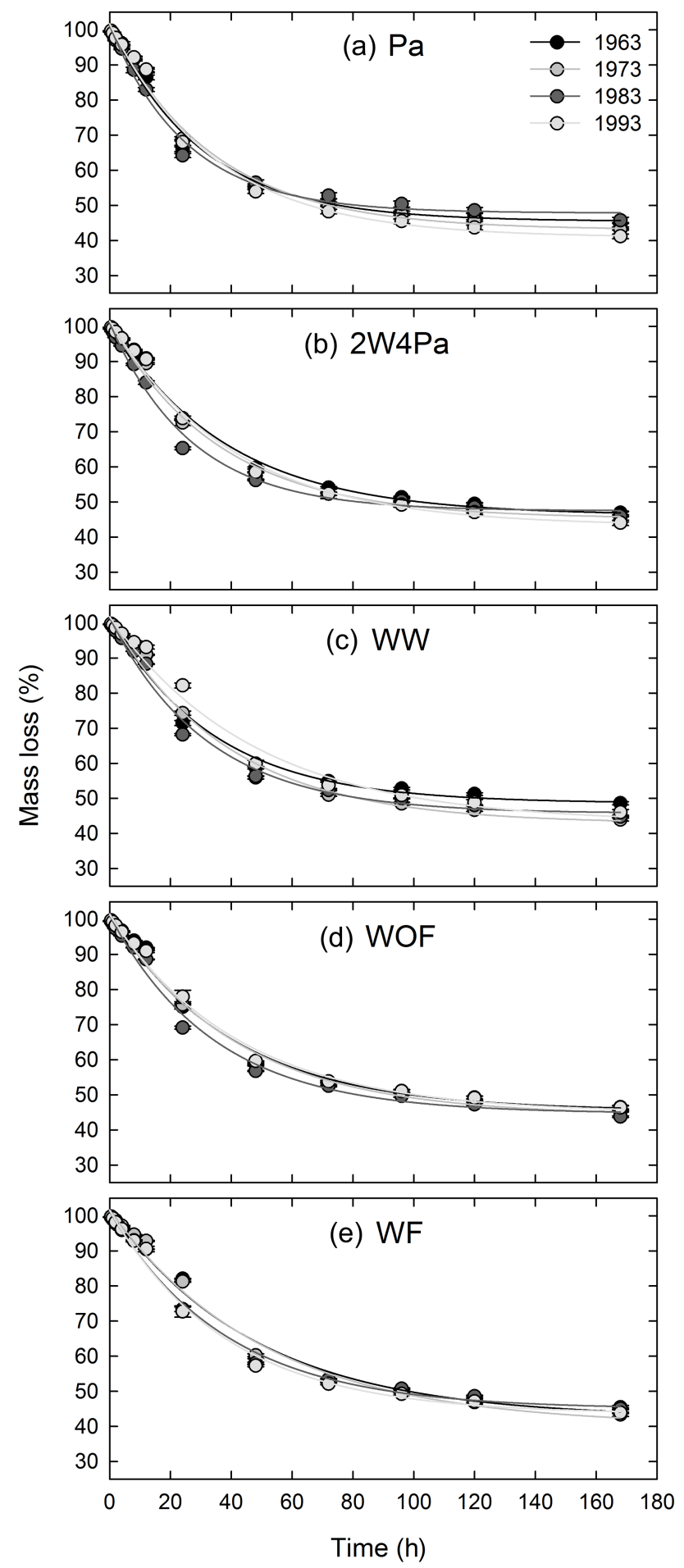

Figure B1. Root exudate incubation results presented as percentage mass loss. Each point represents mean \pm 1 SEM $(n=3)$. Error bars are smaller than symbols. Best-fit single-pool exponential models are also shown (adjusted $R^{2}>0.98$ for all curves). 
Appendix C: Alternate modeling scenario results

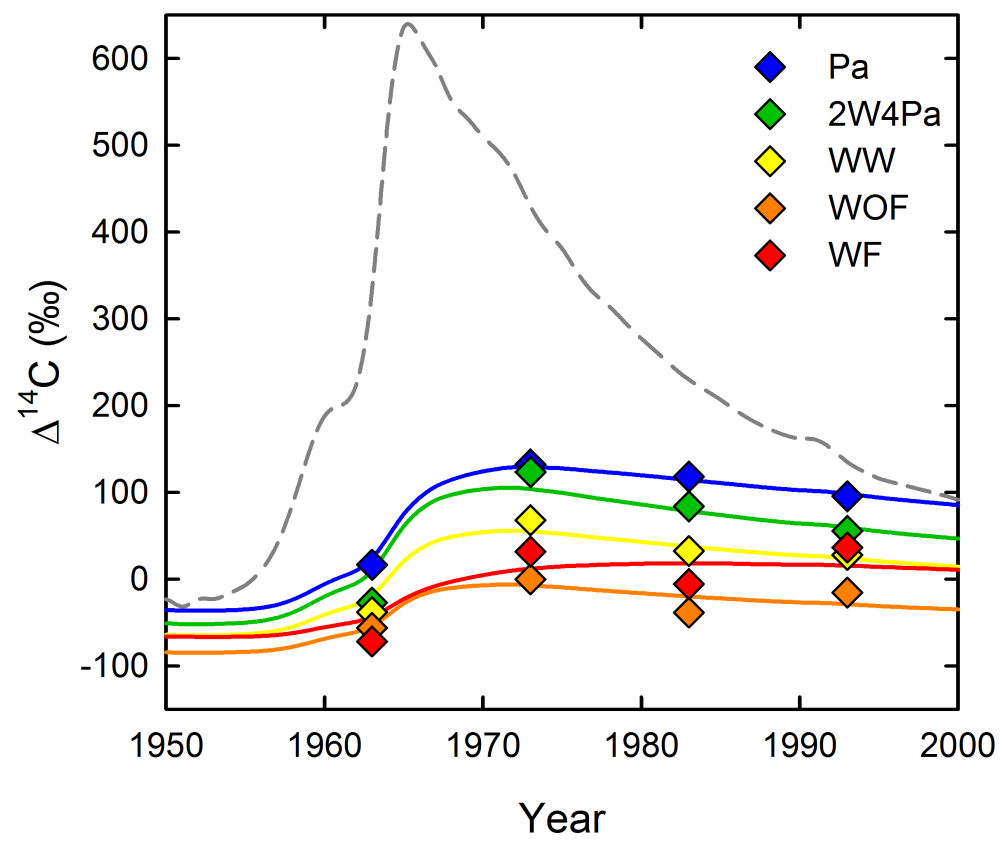

Figure C1. $\Delta^{14} \mathrm{C}$ values of soil organic carbon in upper $10 \mathrm{~cm}$ along with best-fit model solutions for scenario 2 (constant $k_{\text {pool }}$ values

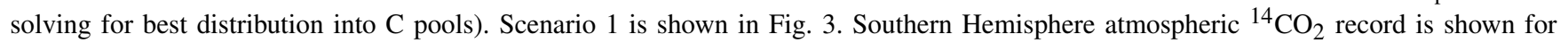
reference (dashed line). 
Author contributions. Stewart Fallon performed the radiocarbon analyses. Jonathan Sanderman and W. Troy Baisden performed the modeling and analysis. Jonathan Sanderman performed the NMR analyses. Courtney Creamer and Mark Farrell conceived the tracer ${ }^{14} \mathrm{C}$ experiment and Courtney Creamer performed amino sugar analyses. Mark Farrell performed and interpreted the tracer ${ }^{14} \mathrm{C}$ experiment. Jonathan Sanderman conceived the study and wrote the first draft of the manuscript, with all authors contributing ideas and revision.

Competing interests. The authors declare that they have no conflict of interest.

Acknowledgements. We would like to thank our predecessors at the Waite Research Institute for having the foresight to archive soil samples from this long-term trial, T. Carter for laboratory assistance, and J. McGowan for assistance in running NMR analyses. Funds for this research were provided by the CSIRO Sustainable Agriculture National Research Flagship and New Zealand public research funding through GNS Science (540GCT82). Mark Farrell was supported by a CSIRO Julius Career Award.

Edited by: B. van Wesemael

Reviewed by: two anonymous referees

\section{References}

Albrecht, W. A.: Loss of soil organic matter and its restoration, in: United States Department of Agriculture, Soils and Men: Yearbook of Agriculture 1938, US Government Printing Office, 347360, 1938.

Allison, S. D. and Martiny, J. B. H.: Resistance, resilience, and redundancy in microbial communities, P. Natl. Acad. Sci. USA, 105, 11512-11519, 2008.

Allison, S. D., Wallenstein, M. D., and Bradford, M. A.: Soil-carbon response to warming dependent on microbial physiology, Nat. Geosci., 3, 336-340, 2010.

Baisden, W. T., Parfitt, R. L., Ross, C., Schipper, L. A., and Canessa, S.: Evaluating 50 years of time-series soil radiocarbon data: toward routine calculation of robust $\mathrm{C}$ residence times, Biogeochemistry, 112, 129-137, 2013.

Baldock, J. A.: Improving the productivity and sustainability of crop rotations through nitrogen management, Grains Research and Development Corporation Final Report UA247, 33 pp., 1998.

Baldock, J. A., Oades, J. M., Nelson, P. N., Skene, T. M., Golchin, A., and Clarke, P.: Assessing the extent of decomposition of natural organic materials using solid-state ${ }^{13} \mathrm{C}$ NMR spectroscopy, Aust. J. Soil Res., 35, 1061-1084, 1997.

Baldock, J. A., Sanderman, J., Macdonald, L. M., Puccini, A., Hawke, B., Szarvas, S., and McGowan, J.: Quantifying the allocation of soil organic carbon to biologically significant fractions, Soil Res., 51, 561-576, 2013a.

Baldock, J. A., Hawke, B., Sanderman, J., and Macdonald, L. M.: Predicting contents of carbon and its component fractions in Australian soils from diffuse reflectance mid-infrared spectra, Soil Res., 51, 577-595, 2013b.
Barré, P., Fernandez-Ugalde, O., Virto, I., Velde, B., and Chenu, C.: Impact of phyllosilicate mineralogy on organic carbon stabilization in soils: incomplete knowledge and exciting prospects, Geoderma, 23, 382-395, 2014.

Blagodatskaya, ̊. and Kuzyakov, Y.: Mechanisms of real and apparent priming effects and their dependence on soil microbial biomass and community structure: critical review, Biol. Fert. Soils, 45, 115-131, 2008.

Blanco-Canqui, H., Shapiro, C. A., Wortmann, C. S., Drijber, R. A., Mamo, M., Shaver, T. M., and Ferguson, R. B.: Soil organic carbon: The value to soil properties, J. Soil Water Conserv., 68, 129A-134A, 2013.

Bustamante, M., Robledo-Abad, C., Harper, R., Mbow, C., Ravindranat, N. H., Sperling, F., Haberl, H., Siqueira Pinto, A., and Smith, P.: Co-benefits, trade-offs, barriers and policies for greenhouse gas mitigation in the agriculture, forestry and other land use (AFOLU) sector, Global Change Biol., 20, 3270-3290, 2014.

Cambardella, C. A. and Elliott, E. T.: Particulate soil organic-matter changes across a grassland cultivation sequence, Soil Sci. Soc. Am. J., 56, 777-783, 1992.

Chappell, A., Baldock, J., and Sanderman, J.: The global significance of omitting soil erosion from soil organic carbon cycling schemes, Nature Climate Change, 6, 187-191, doi:10.1038/ncimate2829, 2015.

Cotrufo, M. F., Wallenstein, M. D., Boot, C. M., Denef, K., and Paul, E.: The Microbial Efficiency-Matrix Stabilization (MEMS) framework integrates plant litter decomposition with soil organic matter stabilization: do labile plant inputs form stable soil organic matter?, Glob. Change Biol., 19, 988-995, 2013.

Cotrufo, M. F., Soong J. L., Horton, A. J., Campbell, E. E., Haddix, M. L., Wall, D. H., and Parton, W. J.: Formation of soil organic matter via biochemical and physical pathways of litter mass loss, Nat. Geosci., 8, 776-779, 2015.

Currie, K. I., Brailsford, G., Nichol, S., Gomez, A., Sparks, R., Lassey, K. R., and Riedel, K.: Tropospheric ${ }^{14} \mathrm{CO}_{2}$ at Wellington, New Zealand: the world's longest record, Biogeochemistry, 104, 5-22, 2011.

Dijkstra, F. A. and Cheng, W.: Interactions between soil and tree roots accelerate long-term soil carbon decomposition, Ecol. Lett., 10, 1046-1053, 2007.

Fang, C., Smith, P., Smith, J. U., and Moncrieff, J. B.: Incorporating microorganisms as decomposers into models to simulate soil organic matter decomposition, Geoderma, 129, 139-146, 2005.

FAO: World reference base for soil resources, World soil resources reports No. 84, Rome, Italy, 1998.

Fallon, S. J., Fifield, L. K., and Chappell, J. M.: The next chapter in radiocarbon dating at the Australian National University: status report on the single stage AMS, Nucl. Instrum. Meth. B., 268, 898-901, 2010.

Fontaine, S., Bardoux, G., Abbadie, L., and Mariotti, A.: Carbon input to soil may decrease soil carbon content, Ecol. Lett., 7, 314 320, 2004.

Grace, P. R., Oades, J. M., Keith, H., and Hancock, T. W.: Trends in wheat yields and soil organic carbon in the Permanent Rotation Trial at the Waite Agricultural Research Institute, South Australia, Aust. J. Exp. Agr., 35, 857-864, 1995.

Janzen, H. H.: The soil carbon dilemma: shall we hoard it or use it?, Soil Biol. Biochem., 38, 419-424, 2006. 
Jenkinson, D. S.: The turnover of organic carbon and nitrogen in soil, Phil. Trans. R. Soc. B, 329, 361-368, 1990.

Jenny, H.: Factors of soil formation, McGraw-Hill, New York, 1941.

Kiem R. and Kogel-Knaber, I.: Contribution of lignin and polysaccharides to the refractory carbon pool in C-depleted arable soils, Soil Biol. Biochem., 35, 101-118, 2003.

Kirkby, C. A., Richardson, A. E., Wade, L. J., Passioura, J. B., Batten, G. D., Blanchard, C., and Kirkegaard, J. A.: Nutrient availability limits carbon sequestration in arable soils, Soil Biol. Biochem., 68, 402-409, 2014.

Kong, A. Y., Six, J., Bryant, D. C., Denison, R. F., and Van Kessel, C.: The relationship between carbon input, aggregation, and soil organic carbon stabilization in sustainable cropping systems, Soil Sci. Soc. Am. J., 69, 1078-1085, 2005.

Kraffczyk, I., Trolldenier, G., and Beringer, H.: Soluble root exudates of maize: influence of potassium supply and rhizosphere microorganisms, Soil Biol. Biochem., 16, 315-322, 1984.

Lajtha, K., Townsend, K. L., Kramer, M. G., Swanston, C., Bowden, R. D., and Nadelhoffer, K.: Changes to particulate versus mineral-associated soil carbon after 50 years of litter manipulation in forest and prairie experimental ecosystems, Biogeochemistry, 119, 341-360, 2014.

Lam, S. K., Chen, D., Mosier, A. R., and Roush, R.: The potential for carbon sequestration in Australian agricultural soils is technically and economically limited, Sci. Rep., 3, 2179, 2013.

Lange, M., Eisenhauer, N., Sierra, C. A., Bessler, H., Engels, C., Griffiths, R. I., Mellado-Vázquez, P. G., Malik, A. A., Roy, J., Scheu, S., and Steinbeiss, S.: Plant diversity increases soil microbial activity and soil carbon storage, Nat. Commun., 6, 6707, 2015.

Lawrence, C. R., Neff, J. C., and Schimel, J. P.: Does adding microbial mechanisms of decomposition improve soil organic matter models? A comparison of four models using data from a pulsed rewetting experiment, Soil Biol. Biochem., 41, 19231934, 2009.

Liang, C. and Balser, T. C.: Preferential sequestration of microbial carbon in subsoils of a glacial-landscape toposequence, Dane County, WI, USA, Geoderma, 148, 113-119, 2008.

Liang, C., Read, H. W., and Balser, T. C.: GC-based detection of aldonitrile acetate derivatized glucosamine and muramic acid for microbial residue determination in soil, J. Vis. Exp., 63, e3767, doi:10.3791/3767, 2012.

Manzoni, S. and Porporato, A.: Soil carbon and nitrogen mineralization: theory and models across scales, Soil Biol. Biochem., 41, 1355-1379, 2009.

Lodge, G. M. and Murphy, S. R.: Root depth of native and sown perennial grass-based pastures, North-West Slopes, New South Wales, 1. Estimates from cores and effects of grazing treatments, Anim. Prod. Sci., 46, 337-345, 2006.

Manzoni, S. and Porporato, A.: Soil carbon and nitrogen mineralization: theory and models across scales, Soil Biol. Biochem., 41, 1355-1379, 2009.

Manzoni, S., Trofymow, J. A., Jackson, R. B., and Porporato, A.: Stoichiometric controls on carbon, nitrogen, and phosphorus dynamics in decomposing litter, Ecol. Monogr., 80, 89-106, 2010.

Miltner, A., Bombach, P., Schmidt-Brücken, B., and Kästner, M.: SOM genesis: microbial biomass as a significant source, Biogeochemistry, 111, 41-55, 2012.
Oldfield, E. E., Wood, S. A., Palm, C. A., and Bradford, M. A.: How much SOM is needed for sustainable agriculture? Front. Ecol. Environ., 13, 527-527, 2015.

Parton, W. J., Schimel, D. S., Cole, C. V., and Ojima, D. S.: Analysis of factors controlling soil organic matter levels in Great Plains grasslands, Soil Sci. Soc. Am. J., 51, 1173-1179, 1987.

Paul, E. A. and Clark, F. E.: Soil microbiology and biochemistry, Academic Press, San Diego, CA, 1986.

Paustian, K., Collins, H. P., and Paul, E. A.: Management controls on soil carbon. Soil organic matter in temperate agroecosystems: Long-term experiments in North America, in: Management controls on soil carbon, CRC Press, Boca Raton, FL, 15-49, 1997.

Paustian, K., Lehmann, J., Ogle, S., Reay, D., Robertson, G. P., and Smith, P.: Climate-smart soils, Nature, 532, 49-57, doi:10.1038/nature17174, 2016.

Rasmussen, P. E. and Parton, W. J.: Long-term effects of residue management in wheat-fallow: I. Inputs, yield, and soil organic matter, Soil Sci. Soc. Am. J., 58, 523-530, 1994.

Read, P.: Biosphere carbon stock management: addressing the threat of abrupt climate change in the next few decades: an editorial essay, Climatic Change, 87, 305-320, 2008.

Richardson, A. E., Hocking, P. J., Simpson, R. J., and George, T. S.: Plant mechanisms to optimise access to soil phosphorus, Crop Pasture Sci., 60, 124-143, 2009.

Sanderman, J., Fillery, I. R. P., Jongepier, R., Massalsky, A., Roper, M. M., Macdonald, L. M., Maddern, T., Murphy, D. V., and Baldock, J. A.: Carbon sequestration under subtropical perennial pastures II: Carbon dynamics, Soil Res., 51, 771-780, 2014.

Sanderman, J., Baisden, W. T., and Fallon, S.: Redefining the inert organic carbon pool, Soil Biol. Biochem., 92, 149-152, 2016.

Schimel, J. P.: Biogeochemical models: implicit vs. explicit microbiology, in: Global Biogeochemical Cycles in the Climate System, editedf by: Schulze, E. D., Harrison, S. P., Heimann, M., Holland, E. A., LLoyd, J. J., Prentice, I. C., and Schimel, D., Academic Press, 177-183, 2001.

Siddique, K. H. M., Belford, R. K., and Tennant, D.: Root: shoot ratios of old and modern, tall and semi-dwarf wheats in a Mediterranean environment, Plant Soil, 121, 89-98, 1990.

Skjemstad, J. O., Clarke, P., Taylor, J. A., Oades, J. M., and Newman, R. H.: The removal of magnetic materials from surface soils - a solid-state C-13 CP/MAS NMR study, Aust. J. Soil Res., 32, 1215-1229, 1994.

Skjemstad, J. O., Spouncer, L. R., Cowie, B., and Swift, R. S.: Calibration of the Rothamsted organic carbon turnover model (RothCver.26.3), using measurable soil organic carbon pools, Aust. J. Soil Res., 42, 79-88, 2004.

Smernik, R. J. and Oades, J. M.: The use of spin counting for determining quantitation in solid state 13-C NMR spectra of natural organic matter, 1 . Model systems and the effects of paramagnetic impurities, Geoderma, 96, 101-129, 2000.

Smith, P.: Soil carbon sequestration and biochar as negative emission technologies. Global Change Biol., 22, 1315-1324, 2016.

Smith, P., Martino, D., Cai, Z., Gwary, D., Janzen, H., Kumar, P., McCarl, B., Ogle, S., O'Mara, F., Rice, C., and Scholes, B.: Greenhouse gas mitigation in agriculture, P. T. R. Soc. B, 363, 789-813, 2008.

Soil Survey Staff: Soil taxonomy: A basic system of soil classification for making and interpreting soil surveys, 2nd edition, Natu- 
ral Resources Conservation Service, US Department of Agriculture Handbook 436, 1999.

Stuiver, M. and Polach, H. A.: Reporting of C-14 data - Discussion, Radiocarbon, 19, 355-363, 1977.

Tian, H., Lu, C., Yang, J., Banger, K., Huntzinger, D. N., Schwalm, C. R., Michalak, A. M., Cook, R., Ciais, P., Hayes, D., and Huang, M.: Global patterns and controls of soil organic carbon dynamics as simulated by multiple terrestrial biosphere models: Current status and future directions, Global Biogeochem. Cy., 29, 775-792, 2015.

Tiessen, H., Cuevas, E., and Chacon, P.: The role of soil organic matter in sustaining soil fertility, Nature, 371, 783-785, 1994.

Trumbore, S. E.: Comparison of carbon dynamics in tropical and temperate soils using radiocarbon measurements, Global Biogeochem. Сy., 7, 275-290, 1993.
Van Oost, K., Quine, T. A., Govers, G., De Gryze, S., Six, J., Harden, J. W., Ritchie, J. C., McCarty, G. W., Heckrath, G., Kosmas, C., Giraldez, J. V., Marques da Silva, J. R., and Merckx, R.: The impact of agricultural soil erosion on the global carbon cycle, Science, 318, 626-629, 2007.

Wardle, D. A., Yeates, G. W., Nicholson, K. S., Bonner, K. I., and Watson, R. N.: Response of soil microbial biomass dynamics, activity and plant litter decomposition to agricultural intensification over a seven-year period, Soil Biol. Biochem., 31, 1707-1720, 1999.

Weider, W. R., Bonan, G. B., and Allison, S. D.: Global soil carbon projections are improved by modelling microbial processes, Nature Clim. Change, 3, 909-912, 2013.

Zhang, X. and Amelung, W.: Gas chromatographic determination of muramic acid, glucosamine, mannosamine, and galactosamine in soils, Soil Biol. Biochem., 28, 1201-1206, 1996. 